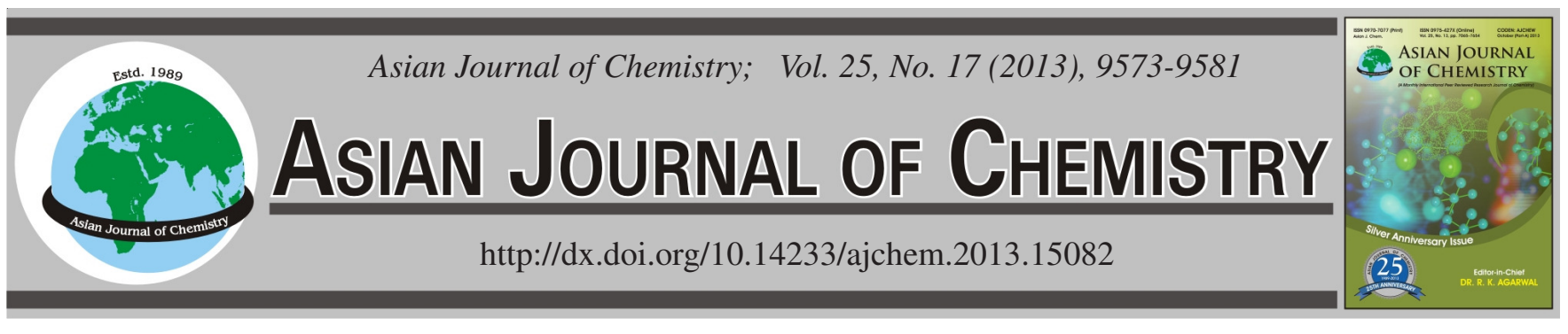

\title{
Isotherms, Kinetics and Thermodynamics of 4-Nitrophenol Adsorption on Fiber-Based Activated Carbon from Coconut Husks Prepared Under Optimized Conditions
}

\author{
Hatem A. Al-Aoh ${ }^{*}$, M. Jamil MaAh, Rosiyah Yahya and M. Radzi Bin Abas
}

Department of Chemistry, Faculty of Science, University of Malaya, 50603 Kuala Lumpur, Malaysia

*Corresponding author: Tel: +60 176243656; E-mail: issa_hatem2@yahoo.com

\begin{abstract}
A study was carried out to investigate the adsorption of 4-nitrophenol on activated carbon fiber prepared from coconut husk. For comparison, a commercially available granular activated carbon was also tested. The effects of initial concentration, agitation time, solution pH and temperature were examined. Adsorption isotherms were described using the Langmuir and Freundlich models. It was found that, both models fit the experimental data. Pseudo-first-order model, pseudo-second-order model and intra-particle diffusion equations were applied to examine the kinetic data. It was noted that the empirical kinetic data of the prepared activated carbon fiber was well described by the pseudo-second-order model, whereas, the pseudo-first-order model agreed well with the experimental data for the commercial granular activated carbon. Intra-particle diffusion mechanism was partially involved in the case of the commercial adsorbent. It was observed that the prepared adsorbent has both the adsorption capacity and a rate of adsorption higher than that of the commercial one. Adsorption thermodynamic parameters were also estimated. Values of $\Delta \mathrm{H}^{\circ}$ with $\Delta \mathrm{S}^{\circ}$ and $\Delta \mathrm{G}^{\circ}$ indicate that the adsorption of 4-nitrophenol onto both adsorbents are exothermic and spontaneous processes. The $\Delta \mathrm{H}^{\circ}$ values suggest that the adsorption is by chemisorption for the prepared activated carbon fiber and physisorption for the commercial granular activated carbon.
\end{abstract}

Key Words: Adsorption, Isotherm, Kinetics, Thermodynamic, Coconut husk, Activated carbon fiber, 4-Nitrophenol.

\section{INTRODUCTION}

Various chemical industries such as petroleum refineries, coal tar, steel foundries, pesticides, insecticides, plastics, preservatives, disinfectants, rubber proofing, pulp processing, pharmaceuticals, gasoline and petrochemicals will usually use phenol or its derivatives as the intermediate ${ }^{1-3}$. Therefore, it is common to find that wastewaters generated from these industries are contaminated by phenolic compounds.

Phenols are normally resistant to biodegradation processes, highly toxic (even at low concentrations) and carcinogenic ${ }^{4-7}$. Thus, the US Environmental Protection Agency (EPA) and the European Union have included most of these compounds, such as phenol, chlorophenols and nitrophenols in their lists of priority pollutants ${ }^{6}$. Consequently, it is mandatory to remove phenolic compounds from wastewaters before their disposal to the environment. Accordingly, various treatment technologies have been used to remove these contaminants from wastewaters. Among these, adsorption is found to be the best technique as is widely used in wastewater treatment ${ }^{8}$.

Powdered and granulated activated carbons are the most widely used adsorbents due to their favorable surface physical and chemical adsorptive properties ${ }^{9}$. Unfortunately, there are some disadvantages that may be associated with these adsorbents when used to remove phenols, such as the high regeneration cost and the generation of fine carbon. This is due to the oligomerization of phenols on its surface under oxic conditions (presence of oxygen) and the brittle nature of these activated carbon ${ }^{3,9-11}$. On the contrary, activated carbon fibers have a number of favorable adsorptive properties such as an elevated adsorption capacity and a high adsorption rate and are easier to handle in a batch system compared to powdered and/or granular activated carbon ${ }^{12}$. Therefore, activated carbon fibers have attracted much attention from many researchers as a new adsorbent for the treatment of polluted gaseous and liquid phases ${ }^{13}$. This is due to their better adsorption performance as compared to the granulated and powdered forms of activated carbons ${ }^{13}$.

Various manufactured fibers like polyacrylonitrile ${ }^{14}$, $\operatorname{poly}(p \text {-phenylene terephthalamide })^{15}, \operatorname{rayon}^{16}, \operatorname{Nomex}[\operatorname{poly}(m-$ phenylene isophthalamide) $]^{17}$, polyvinyl alcohol ${ }^{18}$, phenolic resin $^{19}$ and pitch $^{20}$ have been used for the production of fibrous activated carbons. Those fibers are however, expensive ${ }^{13}$. Thus, one of the main negative aspects of the activated carbon fibers produced from artificial fibers is its higher price compared to the activated carbons available in the market ${ }^{21}$. Therefore, to increase the functionality and application capabilities of 
activated carbon fibers it would be sensible to use low cost materials like natural fibers as precursors for the production of activated carbon fibers. Consequently, few attempts were conducted to prepare this adsorbent from natural precursors such as piassava fibers ${ }^{22}$, kenaf fibers ${ }^{20,23}$, cotton stalks ${ }^{24,25}$, coconut shell fibers ${ }^{26}$, jute and coconut fibers ${ }^{13}$ and oil palm fiber $^{27}$.

Coconut husks are abundant in tropical countries like Malaysia and they often cause serious disposal problems ${ }^{25}$. The fibers obtained from coconut husk have little ash content and are cheap in comparison with industrial fibers ${ }^{13}$. Therefore, activated carbon was prepared from coconut fiber by Phan et $a l .{ }^{13}$ and used for adsorption of phenol, acid red 27 dye and $\mathrm{Cu}^{2+}$ ions. So far, no attempts have been carried out to investigate the adsorption of 4-nitrophenol, on activated carbon prepared from coconut husk fibers under ideal conditions. Thus, the main aim of this work was to determine the optimal conditions of activated carbon production from coconut fiber whereas the second objective was to investigate the adsorption efficiency of the produced sample towards 4-nitrophenol.

It is not easy to determine the real adsorption capacity of phenols due to the oligomerization of these compounds on the adsorbent surface under oxic condition. Therefore, 4-nitrophenol due to its high critical oxidation potential was selected in order to avoid any additional process that may occur simultaneously with the adsorption. Lu et al ${ }^{28}$ reported that the limiting factor in the oligomerization of phenols on the surface of F400 was the oxidation potential which on the other hand is influenced by the functional group of the substituent.

\section{EXPERIMENTAL}

Coconut husk fiber-based activated carbon was prepared using a horizontal tube furnace under optimized experimental conditions established in our primary work. The optimized parameters were; activation temperature of $700{ }^{\circ} \mathrm{C}, 50 \% \mathrm{w} / \mathrm{v}$ $\mathrm{ZnCl}_{2}$ concentration, $200 \mathrm{~cm}^{3} /$ min nitrogen flow rate, activation time of $2 \mathrm{~h}$ and carbonization temperature of $400^{\circ} \mathrm{C}$. The commercial granular activated carbon (ACG; CAS No. 64365-11-3) was obtained from Sigma Aldrich (Germany). The surface areas and porosity of the prepared activated carbon fiber (ACF) and commercial granular activated carbon were measured with a Sorptomatic Automated Gas Sorption System (Sorptomatic Thermo Finnigan 1990, USA) using the BET method. The $\mathrm{pH}$ at the point of zero charge of the prepared activated carbon fiber was determined by using the batch equili-brium method, as described by Babic et al. ${ }^{29}$. Boehm's titration method and the Fourier Transform Infrared Spectroscopy (FT-IR) (Perkin Elmer-2000 FT-IR) measurement was applied to quantify the functional groups on the surfaces of both the prepared activated carbon fiber as well as for the commercial granular activated carbon. To investigate the effect of \% oxygen on the adsorption performances of the prepared sample and the commercial activated carbon, the chemical composition of these two adsorbents was examined by EDX-analyzer. The surface morphology of the adsorbents was examined by scanning electron microscopy (SEM) (LEO 1455 VP, England).

All the chemicals were used without further purification. $\mathrm{HCl}, \mathrm{ZnCl}_{2}, \mathrm{NaHCO}_{3}, \mathrm{Na}_{2} \mathrm{CO}_{3}, \mathrm{NaOH}$ and $\mathrm{NaOC}_{2} \mathrm{H}_{5}, \mathrm{NaNO}_{3}$, $n$-hexane and 4-nitrophenol were purchased from SigmaAldrich, USA, APEO. $10 \mathrm{~g}$ of pure crystals of 4-nitrophenol was weighed and introduced into a $1000 \mathrm{~mL}$ volumetric flask and dissolved in deionized water and diluted up to the mark. Solutions for the adsorption studies were prepared by diluting of this stock solution to the required concentration.

\section{Adsorption studies}

Effect of the initial adsorbate concentration: In batch adsorption experiments, twenty-one solutions of 4-nitrophenol with initial concentrations in the range of $50-1500 \mathrm{mg} / / \mathrm{L}$ were prepared from the stock solution. Certain amounts $(0.03 \mathrm{~g})$ of the prepared activated carbon fiber were added into each of the twenty-one $30 \mathrm{~mL}$ amber bottles each of which containing $25 \mathrm{~mL}$ different concentrations of 4-nitrophenol. The bottles were then sealed and placed in a rotational shaker. The bottles were shaken, at $150 \mathrm{rpm}$, room temperature $\left(30 \pm 1{ }^{\circ} \mathrm{C}\right)$ and without any $\mathrm{pH}$ adjustment, for 3 days in order to reach the adsorption equilibrium. The adsorbent was then separated from the solution by suction filtration. The final concentrations of 4-nitrophenol at equilibrium $\left(\mathrm{C}_{\mathrm{e}}\right)$ were measured by using a UV-visible spectrophotometer (Shimadzu, Japan) at a maximum wavelength of $317 \mathrm{~nm}$. The amount adsorbed at equilibrium was calculated based on eqn. 1 .

$$
\mathrm{q}_{\mathrm{e}}=\frac{\left(\mathrm{C}_{\mathrm{o}}-\mathrm{C}_{\mathrm{e}}\right) \mathrm{V}}{\mathrm{W}}
$$

where, $\mathrm{C}_{0}$ and $\mathrm{C}_{\mathrm{e}}$ are the liquid phase concentrations of 4-nitrophenol at initial and equilibrium times, respectively. $\mathrm{V}$ is the volume of the solution (L) whereas, W is the mass of adsorbent (g).

For comparison, the above-mentioned processes were repeated with commercial granular activated carbon.

Adsorption isotherms: The study of the adsorption isotherms was performed by adding $25 \mathrm{~mL}$ of 400, 450, 500, 550 and $600 \mathrm{mg} / \mathrm{L}$ solutions of 4-nitrophenol into amber bottles, each bottle containing a fixed amount $(0.03 \mathrm{~g})$ of the prepared activated carbon fiber or the commercially available granular activated carbon. The bottles were sealed and shaken at $150 \mathrm{rpm}$ on a rotational shaker at room temperature $(30 \pm 1$ ${ }^{\circ} \mathrm{C}$ ) for 3 days without any $\mathrm{pH}$ adjustment. The mixtures were then separated by filtration. The final concentrations of 4-nitrophenol at equilibrium were measured. The amounts of 4-nitrophenol adsorbed at equilibrium by the adsorbents $\left(q_{\mathrm{e}}\right.$ $\mathrm{mg} / \mathrm{g}$ ) were also calculated from eqn. 1 .

Adsorption kinetics: To investigate the effect of contact time and the adsorption kinetics, the adsorption of 200 and $400 \mathrm{mg} / \mathrm{L}$ of 4-nitrophenol solutions on the prepared activated carbon fiber and commercial granular activated carbon were carried out at predetermined time intervals. A similar procedure as conducted with the isotherm studies were followed. The uptake of 4-nitrophenol at any time $\mathrm{t}\left(\mathrm{q}_{\mathrm{t}} \mathrm{mg} / \mathrm{g}\right)$ was calculated using the following equation:

$$
\mathrm{q}_{\mathrm{t}}=\frac{\left(\mathrm{C}_{\mathrm{o}}-\mathrm{C}_{\mathrm{t}}\right) \mathrm{V}}{\mathrm{W}}
$$

where, $\mathrm{q}_{\mathrm{t}}$ is the amount of 4-nitrophenol adsorbed at time $\mathrm{t}$ $(\mathrm{mg} / \mathrm{g}) . \mathrm{C}_{\mathrm{o}}$ and $\mathrm{C}_{\mathrm{t}}(\mathrm{mg} / \mathrm{L})$ are the liquid phase concentrations at initial and any time $\mathrm{t}$, respectively. $\mathrm{V}$ is the volume of the solution (L) and W is the mass of adsorbent $(\mathrm{g})$. 
Effect of solution pH: $100 \mathrm{~mL}$ of $450 \mathrm{mg} / \mathrm{L}$ 4-nitrophenol solution was added to each one of the six beakers $(200 \mathrm{~mL})$. The $\mathrm{pH}$ of the solutions was adjusted to the required values (2-11) by the addition of $\mathrm{HCl}$ or $\mathrm{NaOH}$. $25 \mathrm{~mL}$ of each solution was then added to the amber bottles containing $0.03 \mathrm{~g}$ of the prepared activated carbon fiber as well as for the commercial granular activated carbon. The experiments were performed at room temperature $\left(30 \pm 1^{\circ} \mathrm{C}\right)$ and at $150 \mathrm{rpm}$ and the samples separated by filtration after 3 days. The final concentrations of 4-nitrophenol and the amount adsorbed at equilibrium were measured and calculated, respectively, as in the isotherm studies.

Adsorption thermodynamics: The same processes carried out in the isotherm studies were repeated at 30,45 and $60^{\circ} \mathrm{C}$ with two different initial concentrations of 4-nitrophenol (400 and $450 \mathrm{mg} / \mathrm{L}$ ) using an incubator shaker. The experiments were carried out in order to study the impact of temperature on the adsorption capacities and to investigate the adsorption thermodynamic parameters such as $\Delta \mathrm{H}^{\mathrm{o}}, \Delta \mathrm{G}^{\mathrm{o}}$ and $\Delta \mathrm{S}^{\mathrm{o}}$

\section{RESULTS AND DISCUSSION}

Characteristics of the adsorbents: The BET surface areas of the prepared activated carbon fiber and the commercial granular activated carbon were found to be 1354 and 1061 $\mathrm{m}^{2} / \mathrm{g}$, respectively. The pore structure of the prepared activated carbon was calculated to be $89.1 \%$ micropores and $10.9 \%$ mesopores with an average pore diameter of $1.952 \mathrm{~nm}$. For the commercial granular activated carbon, the calculations gave $58.6 \%$ micropores and $41.4 \%$ mesopores and macropores with an average pore diameter of $2.106 \mathrm{~nm}$. The $\mathrm{pH}$ at the point of zero charge ( $\mathrm{pHZPC}$ ) of the prepared activated carbon was found to be 6.0. The results of Boehm's titration method showed no difference between the concentrations of the standard and the final solutions. The $\mathrm{pH}$ ZPC value and Boehm's titration results indicated that the surface of the prepared activated carbon fiber is naturally neutral. The results of the FR-IR spectra of the prepared activated carbon fiber and the commercial granular activated carbon are presented in Fig. 1. This figure shows that the absorption peaks appeared in the region of 3423.64 and $3434.43 \mathrm{~cm}^{-1}$ for the prepared sample and for the commercial one, respectively. Both of these peaks represent $\mathrm{OH}$ vibration stretching. The band recorded in the region of $2961 \mathrm{~cm}^{-1}$ in the case of the prepared activated carbon corresponds to an aliphatic $\mathrm{CH}_{2}$ - bending vibration (Fig. 1). Moreover, there are two main absorption peaks recorded in the regions of 1053 and $1633.36 \mathrm{~cm}^{-1}$ for the prepared activated carbon fiber and granular activated carbon, respectively. These two peaks correspond to the mono or disubstituted $\mathrm{C}=\mathrm{C}$. The FT-IR results indicate that both adsorbents have the same absorption peaks and differ only in the absence of $\mathrm{CH}_{2}$-bending vibration in the region of $2961 \mathrm{~cm}^{-1}$ for the commercial activated carbon. Furthermore, the results obtained by the EDX analyzer showed that the prepared activated carbon contains a very small amount of oxygen (6.15). The SEM photograph of the prepared activated carbon fiber and the commercial granular activated carbon are given in Figs. 2 and 3, respectively. It can be observed from this figures that most of the pores on the surface of activated carbon fiber are micropores, which are more effective in the case of the adsorption of 4-nitrophenol.

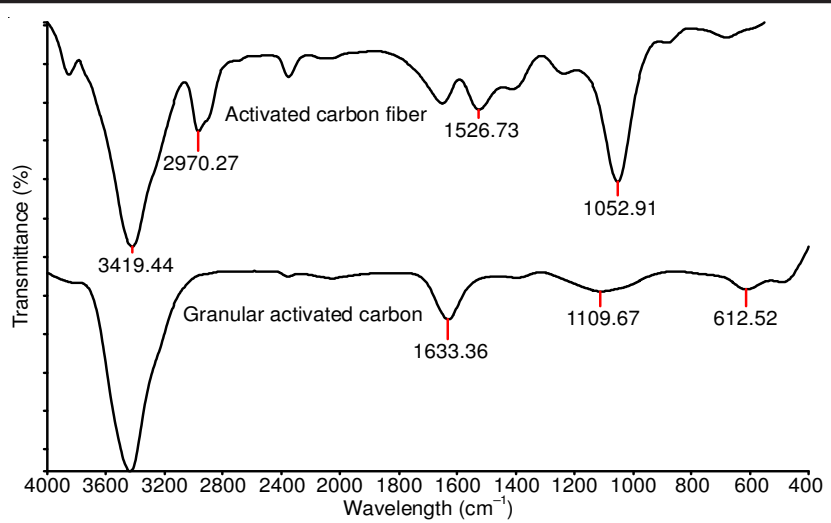

Fig. 1. FT-IR graph of coconut husk fiber-based activated carbon and granular activated carbon

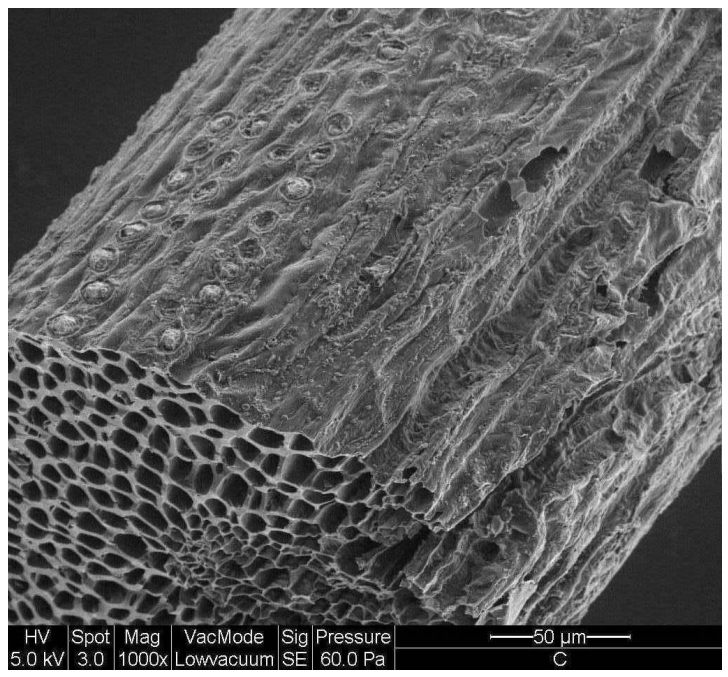

Fig. 2. SEM image of activated carbon fiber

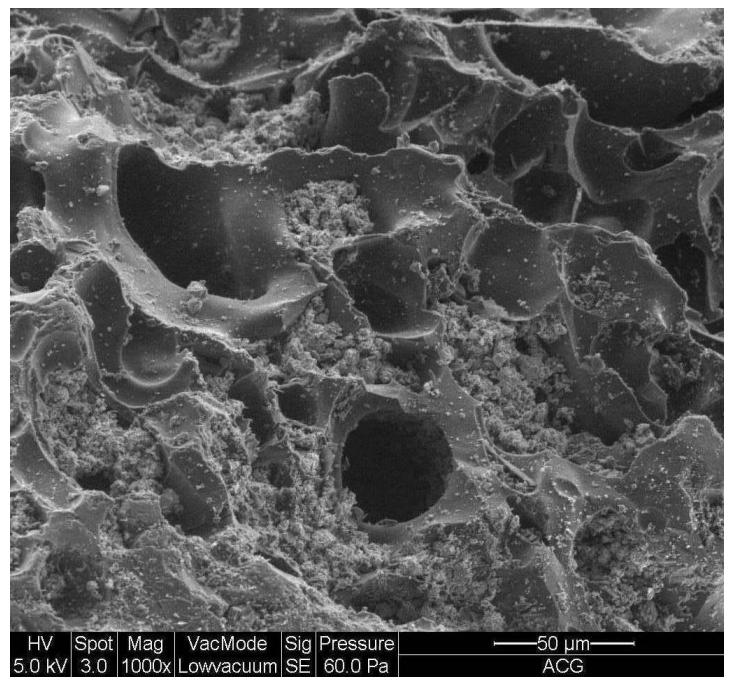

Fig. 3. SEM image of granular activated carbon

In the other hand, the majority of pores on the surface of granular activated carbon are mesopores, which are less effective in the adsorption of 4-nitrophenol.

\section{Adsorption studies}

Effect of initial concentrations: Fig. 4 shows the effect of the initial concentrations $\left(\mathrm{C}_{0} \mathrm{mg} / \mathrm{L}\right)$ of the solution on the adsorption efficiency of the prepared activated carbon and the 
commercial activated carbon. It can be observed from this figure that, the amount adsorbed at equilibrium $\left(\mathrm{q}_{\mathrm{e}} \mathrm{mg} / \mathrm{g}\right)$ of both adsorbents increases as the 4-nitrophenol concentration increased from $50-1000 \mathrm{mg} / \mathrm{L}$ and becomes stable when the concentration is increased above $1000 \mathrm{mg} / \mathrm{L}$. Fig. 4 also illustrates that the prepared activated carbon fiber is more effective in adsorbing 4-nitrophenol compared to the commercial granular activated carbon. This is due to its higher surface area and higher percentage of micropores.

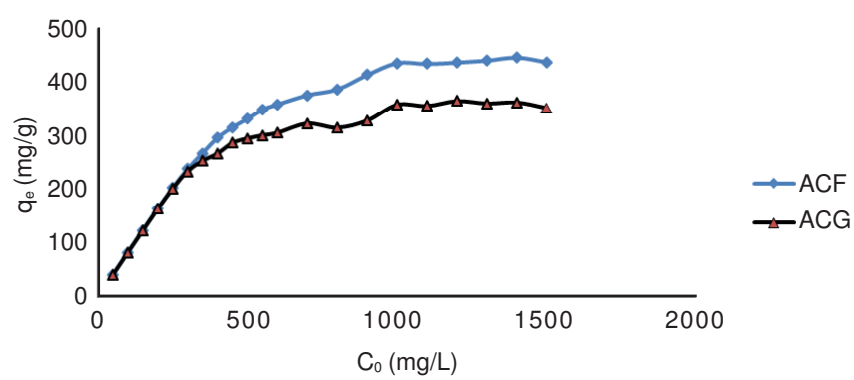

Fig. 4. Effect of initial concentration on the adsorption capacity of 4nitrophenol on activated carbon fiber (ACF) and commercial granular activated carbon (ACG)

Adsorption isotherms: Adsorption isotherm is a fundamental concept in adsorption science ${ }^{30}$. It is the equilibrium relationship between the amount of the substance adsorbed and its pressure or concentration in the bulk fluid phase at a constant temperature ${ }^{30,31}$. The primary experimental information is usually made up by these isotherms, commonly used as a tool to distinguish among different adsorbents and by this means selecting the fitting one for a particular application ${ }^{32}$. Several models such as Langmuir, Freundlich, Temkin, Dubinin-Radshkevich (D-R) and Redlich-Peterson (R-P) are available in literature to describe the experimental data of the adsorption isotherms. The Langmuir model is based on the supposition of a homogeneous adsorbent surface with identical adsorption sites ${ }^{33}$. The Freundlich model is an empirical equation which is based on the assumption that there are heterogeneous adsorptive energies on the surface of the adsorbent ${ }^{33}$. RedlichPeterson's model is usually used as a compromise between the Langmuir and the Freundlich models ${ }^{33}$. When $\beta$ values are close to unity, the Redlich-Peterson's isotherms conform to the Langmuir model better than that of the Freundlich model ${ }^{33}$.

In this work, both Langmuir and Freundlich isotherm models were used to analyze the adsorption equilibrium data. The linear form of these two models is given by eqns. 3 and 4 for Langmuir and Freundlich, respectively:

$$
\begin{aligned}
& \frac{\mathrm{C}_{\mathrm{e}}}{\mathrm{q}_{\mathrm{e}}}=\frac{1}{\mathrm{q}_{\max } \mathrm{K}_{\mathrm{L}}}+\frac{\mathrm{C}_{\mathrm{e}}}{\mathrm{q}_{\max }} \\
& \ln \mathrm{q}_{\mathrm{e}}=\ln \mathrm{K}_{\mathrm{F}}+\frac{1}{\mathrm{n}} \ln \mathrm{C}_{\mathrm{e}}
\end{aligned}
$$

where, $\mathrm{q}_{\mathrm{e}}$ is the amount of an adsorbate adsorbed at equilibrium (mg/g), $\mathrm{q}_{\max }$ the maximum adsorption capacity corresponding to a complete monolayer coverage on the surface $(\mathrm{mg} / \mathrm{g}), \mathrm{C}_{\mathrm{e}}$ is the concentration of the adsorbate at equilibrium $(\mathrm{mg} / \mathrm{L})$. $\mathrm{K}_{\mathrm{L}}$ is the Langmuir constant. $\mathrm{K}_{\mathrm{F}}$ is the Freundlich constant in relation to the adsorption capacity. $1 / \mathrm{n}$ is another constant in the Freundlich model related to adsorption. If the value of $1 / \mathrm{n}$ is between 0 and 1 , this indicates that the adsorption is favourable ${ }^{34}$.

The essential characteristics of the Langmuir equation can be articulated in the vocabulary of a dimensionless factor, $\mathrm{R}_{\mathrm{L}}$ which is given by eqn. $5^{35}$.

$$
\mathrm{R}_{\mathrm{L}}=\frac{1}{1+\mathrm{K}_{\mathrm{L}} \mathrm{C}_{0}}
$$

where, $\mathrm{K}_{\mathrm{L}}$ is the Langmuir constant and is the highest initial concentration of the adsorbate. The $\mathrm{R}_{\mathrm{L}}$ value implies that the adsorption to be unfavorable $\left(\mathrm{R}_{\mathrm{L}}>1\right)$, linear $\left(\mathrm{R}_{\mathrm{L}}=1\right)$, favourable $\left(0<\mathrm{R}_{\mathrm{L}}<1\right)$ or irreversible $\left(\mathrm{R}_{\mathrm{L}}=0\right)$.

In case of the Langmuir equation, the relationship between $\mathrm{C}_{\mathrm{e}} / \mathrm{q}_{\mathrm{e}}$ and $\mathrm{C}_{\mathrm{e}}$ for both the prepared $\mathrm{ACF}$ and the commercial granular activated carbon is given in Fig. 5. Langmuir parameter's $\mathrm{q}_{\max }$ and $\mathrm{K}_{\mathrm{L}}$ were calculated from the slopes and intercepts of those plots, respectively. Values of these two parameters, the correlation coefficients $\left(\mathrm{R}^{2}\right)$ and $\mathrm{R}_{\mathrm{L}}$ are listed in Table- 1 .

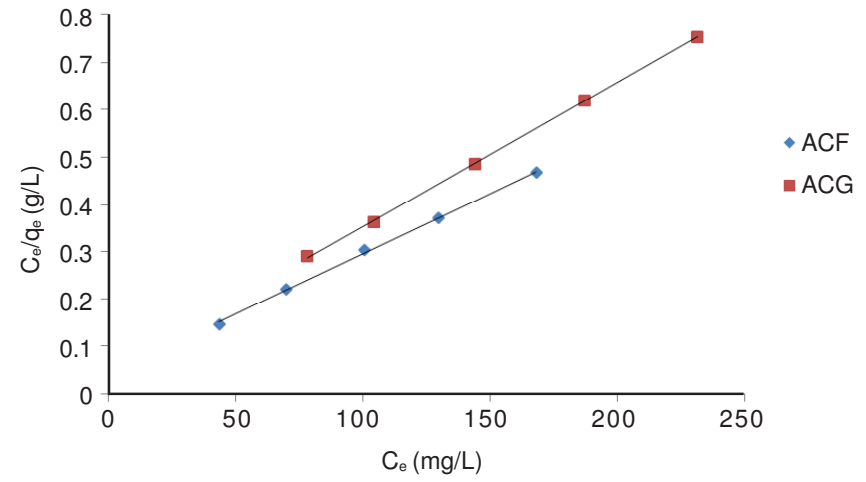

Fig. 5. Langmuir isotherm model for adsorption of 4-nitrophenol on activated carbon fiber and commercial granular activated carbon

From the slope and intercept of the linear plots of $\ln \mathrm{q}_{\mathrm{e}}$ versus $\ln \mathrm{C}_{\mathrm{e}}$ (Fig. 6), 1/n and $\mathrm{K}_{\mathrm{F}}$ (Freundlich parameters), respectively, were obtained and listed with the correlation coefficient value $\left(\mathrm{R}^{2}\right)$ in Table-1. It can be observed from Table1 that the prepared activated carbon fiber has an adsorption capacity $(500 \mathrm{mg} / \mathrm{g})$ higher than that of the commecial granular activated carbon $(333.3 \mathrm{mg} / \mathrm{g})$. Moreover, the Freundlich constant $\left(\mathrm{K}_{\mathrm{F}}=171.74\right)$ of the prepared activated carbon is also larger than that obtained for the granular activated carbon $\left(\mathrm{K}_{\mathrm{F}}=164.02\right)$. The results indicate that the prepared adsorbent has high adsorption affinity towards 4-nitrophenol than the

TABLE-1

\begin{tabular}{|c|c|c|c|c|c|c|c|c|}
\hline \multirow{2}{*}{ Adsorbent } & \multicolumn{4}{|c|}{ Langmuir isotherm } & \multicolumn{4}{|c|}{ Freundlich isotherm } \\
\hline & $\mathrm{q}_{\max }(\mathrm{mg} / \mathrm{g})$ & $\mathrm{K}_{\mathrm{L}}(\mathrm{L} / \mathrm{mg})$ & $\mathrm{R}_{\mathrm{L}}$ & $\mathrm{R}^{2}$ & $\mathrm{~K}_{\mathrm{F}}(\mathrm{mg} / \mathrm{g})(\mathrm{L} / \mathrm{mg})^{1 / \mathrm{n}}$ & $1 / \mathrm{n}$ & $\mathrm{n}$ & $\mathrm{R}^{2}$ \\
\hline $\mathrm{ACF}$ & 500 & 0.051 & 0.032 & 0.999 & 171.74 & 0.144 & 6.9 & 0.995 \\
\hline $\mathrm{ACG}$ & 333.3 & 0.061 & 0.027 & 0.999 & 164.02 & 0.117 & 8.5 & 0.920 \\
\hline
\end{tabular}

LANGMUIR, FREUNDLICH PARAMETERS AND SEPARATION FACTORS $\left(\mathrm{R}_{\mathrm{L}}\right)$ FOR THE ADSORPTION OF 4-NITROPHENOL ON ACTIVATED CARBON FIBER (ACF) AND COMMERCIAL GRANULAR ACTIVATED CARBON (ACG) 


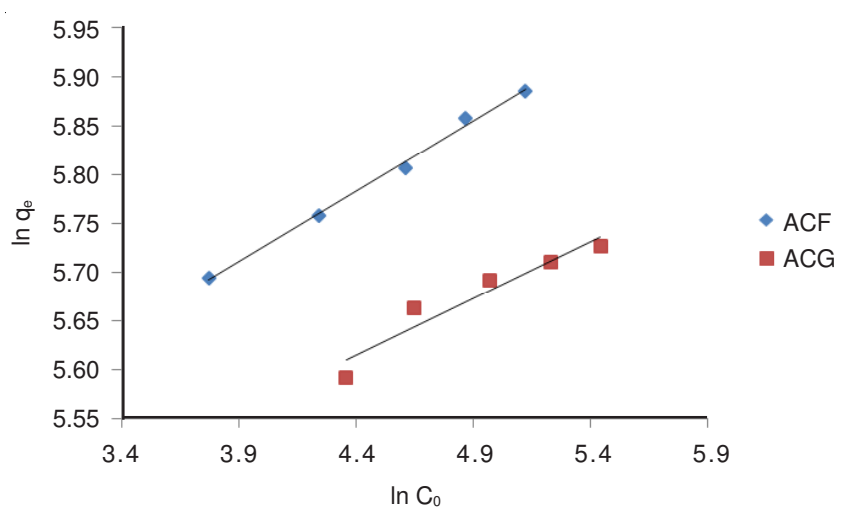

Fig. 6. Freundlich isotherm model for adsorption of 4-nitrophenol on activated carbon fiber and commercial granular activated carbon

commercial sample. This is due to the larger surface area and a higher percentage of micropores in the prepared activated carbon, which is more effective in the adsorption process. Furthermore, it can be seen from Table-1 that all values of $\mathrm{R}_{\mathrm{L}}$ and $1 / \mathrm{n}$ are in between zero and one. This confirms that the adsorption of 4-nitrophenol on both the prepared activated carbon fiber and the commercial granular activated carbon is favorable. Values of the correlation coefficients $\left(\mathrm{R}^{2}\right)$ along with Figs. 4 and 5 demonstrate that the Langmuir isotherm model fits well with the equilibrium data. The Freundlich model also reveals a good correlation, with $\mathrm{R}^{2}$ values of 0.920 and 0.995 for the prepared activated carbon and the commercial one, respectively. Similar results were observed previously by Ahmad et al. ${ }^{36}$.

Effect of agitation time: Plots of the amount adsorbed $\left(\mathrm{q}_{\mathrm{t}} \mathrm{mg} / \mathrm{g}\right)$ versus time $(\mathrm{t} \mathrm{min})$ are depicted in Figs. 7 and 8 for the prepared activated carbon fiber and the commercial granular activated carbon, respectively. It can be seen from these figures that the amount adsorbed increases as the agitation time increased until reaching equilibrium at 1 and $3 \mathrm{~h}$ for the prepared activated carbon fiber and the commercial granular activated carbon, respectively. This confirms that the rate of adsorption on the prepared activated carbon fiber is higher than that of the commercial granular activated carbon. This is due to all the micropores being directly on the surface of the activated carbon-fiber ${ }^{37}$, whereas, the adsorption of phenols on granular activated carbon involves intra-particular diffusion ${ }^{38}$.

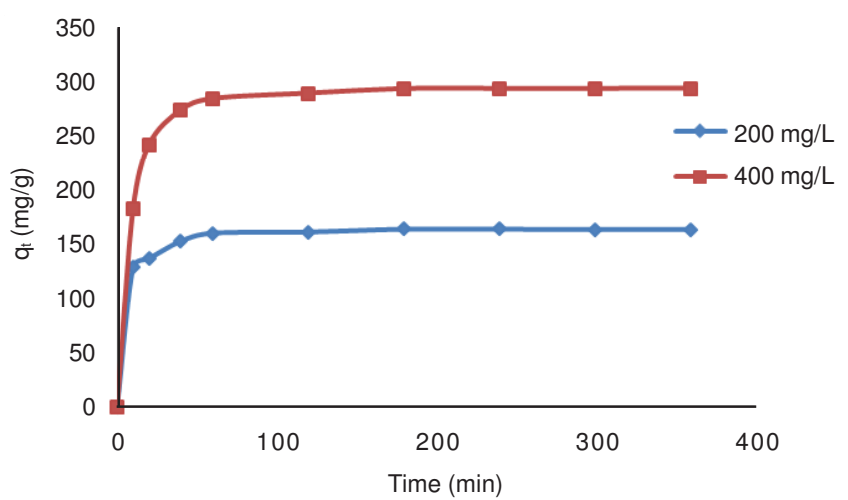

Fig. 7. Plot of $\mathrm{q}_{\mathrm{t}}$ versus time for the adsorption of 4-nitrophenol onto activated carbon fiber at two initial concentrations $(200 \mathrm{mg} / \mathrm{L}, 400$ $\mathrm{mg} / \mathrm{L})$

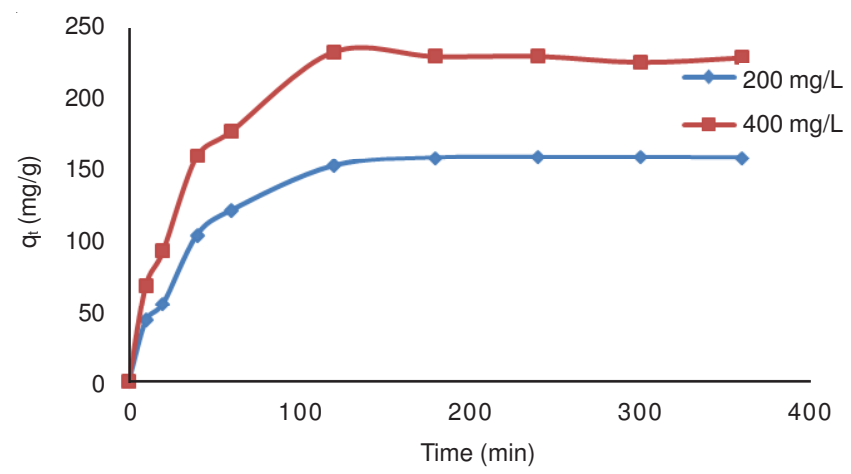

Fig. 8. Plot of $\mathrm{q}_{\mathrm{t}}$ versus time for the adsorption of 4-nitrophenol onto commercial granular activated carbon at two initial concentrations (200 mg/L, $400 \mathrm{mg} / \mathrm{L})$

Adsorption kinetics: The adsorption kinetics of 4nitrophenol on both activated carbon fiber and commercial granular activated carbon were studied using initial concentrations of 4-nitrophenol of 200 and $400 \mathrm{mg} / \mathrm{L}$. The linear forms of the pseudo-first-order Lagergren (eqn. 6), pseudo-secondorder rate equation (eqn. 7) and intra-particle diffusion equation (eqn. 8) have been used in this work to model the adsorption kinetics.

$$
\begin{gathered}
\log \left(\mathrm{q}_{\mathrm{e}}-\mathrm{q}_{\mathrm{t}}\right)=\log \mathrm{q}_{\mathrm{e}}-\mathrm{K}_{1} \frac{\mathrm{t}}{2.303} \\
\frac{\mathrm{t}}{\mathrm{q}_{\mathrm{t}}}=\frac{1}{\mathrm{~K}_{2} \mathrm{q}_{\mathrm{e}}^{2}}+\frac{\mathrm{t}}{\mathrm{q}_{\mathrm{e}}} \\
\mathrm{q}_{\mathrm{t}}=\mathrm{K}_{\text {dif }} \sqrt{\mathrm{t}}+\mathrm{C}
\end{gathered}
$$

where, $\mathrm{q}_{\mathrm{e}}(\mathrm{mg} / \mathrm{g})$ and $\mathrm{q}_{\mathrm{t}}(\mathrm{mg} / \mathrm{g})$ are the amounts of 4-nitrophenol adsorbed at equilibrium and at any time $\mathrm{t}(\mathrm{min})$, respectively. $\mathrm{K}_{1}\left(\mathrm{~h}^{-1}\right), \mathrm{K}_{2}(\mathrm{~g} / \mathrm{mg} \mathrm{h})$ and $\mathrm{K}_{\text {dif }}\left(\mathrm{mg} / \mathrm{g} \mathrm{h}^{1 / 2}\right)$ are the rate constants of the pseudo-first-order, pseudo-second-order and intraparticle diffusion models, respectively. $\mathrm{C}$ is another constant, which gives information about the thickness of the boundarylayer $^{36}$.

Linear plots of all the considered kinetic models are depicted in Figs. 9-14. Adsorption kinetic parameters have been calculated from the slope and intercept of these plots and are given with the correlation coefficients in Tables 2 and 3.

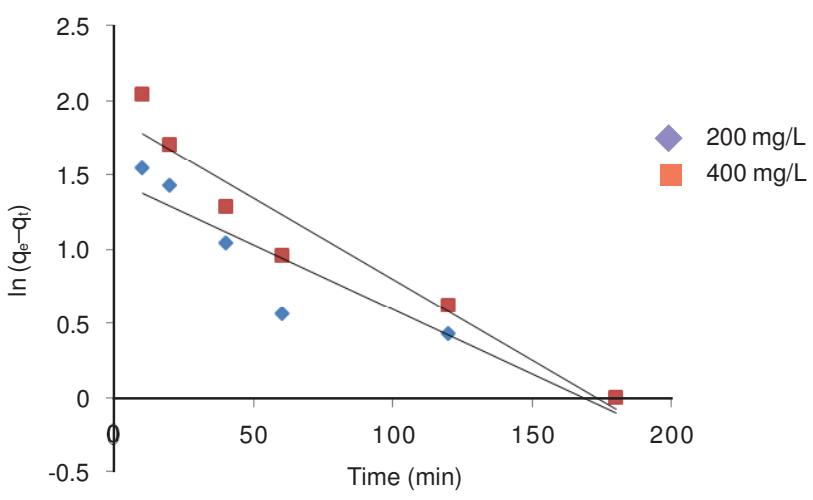

Fig. 9. Pseudo first-order kinetics model for the adsorption of 4-nitrophenol onto activated carbon fiber 
TABLE-2

PSEUDO-FIRST AND PSEUDO-SECOND ORDER ADSORPTION RATE CONSTANTS, THE CALCULATED AND EXPERIMENTAL

$\mathrm{q}_{\mathrm{e}}$ VALUES FOR THE ADSORPTION OF 4-NITROPHENOL ONTO ACTIVATED CARBON FIBER (ACF) AND GRANULAR ACTIVATED CARBON (ACG) AT DIFFERENT INITIAL CONCENTRATIONS AND $30 \pm 1{ }^{\circ} \mathrm{C}$

\begin{tabular}{|c|c|c|c|c|c|c|c|c|c|}
\hline \multirow{2}{*}{ Adsorbent } & \multirow{2}{*}{$\mathrm{C}_{0}(\mathrm{mg} / \mathrm{L})$} & \multirow{2}{*}{$\mathrm{q}_{\mathrm{e}, \exp }(\mathrm{mg} / \mathrm{g})$} & \multicolumn{3}{|c|}{ Pseudo-first-order model } & \multicolumn{4}{|c|}{ Pseudo-second-order model } \\
\hline & & & $\mathrm{q}_{\mathrm{e}, \mathrm{cal}}(\mathrm{mg} / \mathrm{g})$ & $\mathrm{K}_{1}\left(\mathrm{~h}^{-1}\right)$ & $\mathrm{R}^{2}$ & $\mathrm{q}_{\mathrm{e}, \mathrm{cal}}(\mathrm{mg} / \mathrm{g})$ & $\mathrm{K}_{2}(\mathrm{~g} / \mathrm{mg} \mathrm{h})$ & $\mathrm{R}^{2}$ & Rate \\
\hline \multirow{2}{*}{$\mathrm{ACF}$} & 200 & 164.39 & 28.77 & 0.018 & 0.886 & 166.67 & 0.00180 & 0.999 & 0.299 \\
\hline & 400 & 249.56 & 77.09 & 0.023 & 0.934 & 333.3 & 0.00056 & 0.999 & 0.188 \\
\hline \multirow{2}{*}{ ACG } & 200 & 158.75 & 175.79 & 0.028 & 0.997 & 200 & 0.00012 & 0.990 & 0.024 \\
\hline & 400 & 230.83 & 249.46 & 0.035 & 0.906 & 333.3 & 0.00008 & 0.991 & 0.025 \\
\hline
\end{tabular}

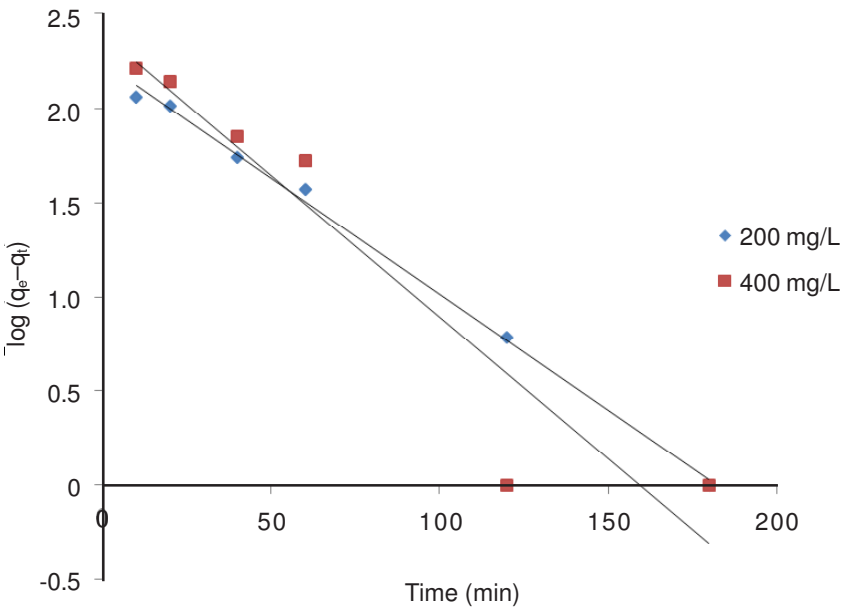

Fig. 10. Pseudo first-order kinetics model for the adsorption of 4-nitrophenol onto commercial granular activated carbon

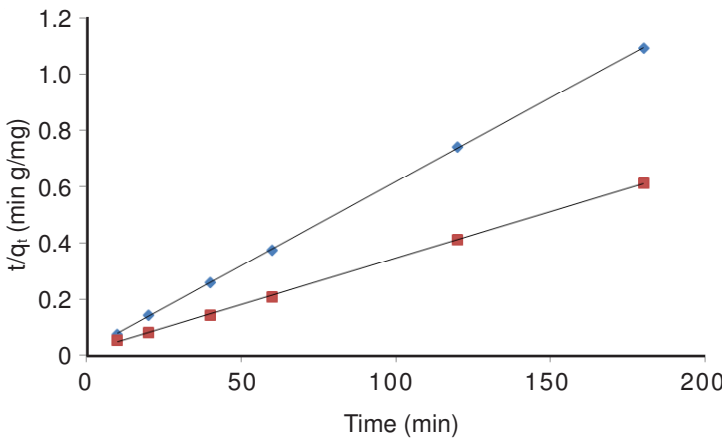

$-200 \mathrm{mg} / \mathrm{L}$

$=400 \mathrm{mg} / \mathrm{L}$

Fig. 11. Pseudo second-order kinetics model for the adsorption of 4nitrophenol onto activated carbon fiber

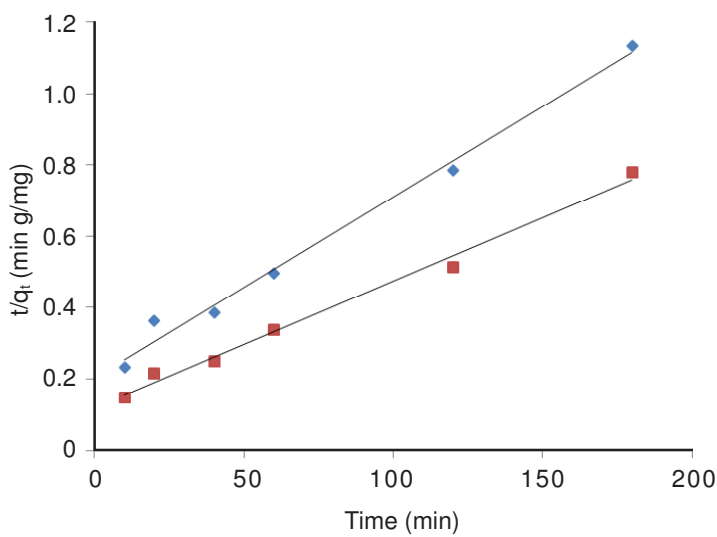

Fig. 12. Pseudo second-order kinetics model for the adsorption of 4nitrophenol onto commercial granular activated carbon

\begin{tabular}{cccccc}
\multicolumn{6}{c}{ TABLE-3 } \\
\multicolumn{5}{c}{ PARAMETER VALUES OF INTRA-PARTICLE } \\
DIFFUSION MODEL FOR THE ADSORPTION OF \\
4-NITROPHENOL ONTO ACF AND ACG AT DIFFERENT \\
INITIAL CONCENTRATIONS AND 30 $\pm 1^{\circ} \mathrm{C}$ \\
\hline \multirow{2}{*}{ Sample } & $\mathrm{C}_{0}$ & $\mathrm{q}_{\mathrm{e}, \mathrm{exp}}$ & \multicolumn{3}{c}{ Intra-particle diffusion parameter } \\
\cline { 4 - 6 } & $(\mathrm{mg} / \mathrm{L})$ & $(\mathrm{mg} / \mathrm{g})$ & $\mathrm{K}_{\mathrm{dif}}\left(\mathrm{mg} / \mathrm{h}^{1 / 2} \mathrm{~g}\right)$ & $\mathrm{C}$ & $\mathrm{R}^{2}$ \\
\hline \multirow{2}{*}{ ACF } & 200 & 164.39 & 3.314 & 125.6 & 0.787 \\
& 400 & 249.56 & 8.924 & 193.4 & 0.663 \\
\hline \multirow{2}{*}{ ACG } & 200 & 158.75 & 11.91 & 14.22 & 0.918 \\
& 400 & 230.83 & 16.80 & 31.46 & 0.905 \\
\hline
\end{tabular}

Figs. 9-14 along with Tables 2 and 3 indicate that the pseudo-second-order model adequately describes the adsorption kinetics of 4-nitrophenol on the prepared activated carbon fiber with a high correlation coefficient $\left(\mathrm{R}^{2}=0.999\right)$. Moreover, it can be observed that the values of the calculated $\mathrm{q}_{\mathrm{e}}$ are in a good agreement with experimental $\mathrm{q}_{\mathrm{e}}$ values. This means that the adsorption of 4-nitrophenol on the prepared activated carbon is by chemisorptions ${ }^{39,40}$. Tang et al. ${ }^{41}$ also found that the adsorption of 4-nitrophenol on activated carbon fiber obeyed the pseudo-second-order kinetics model.

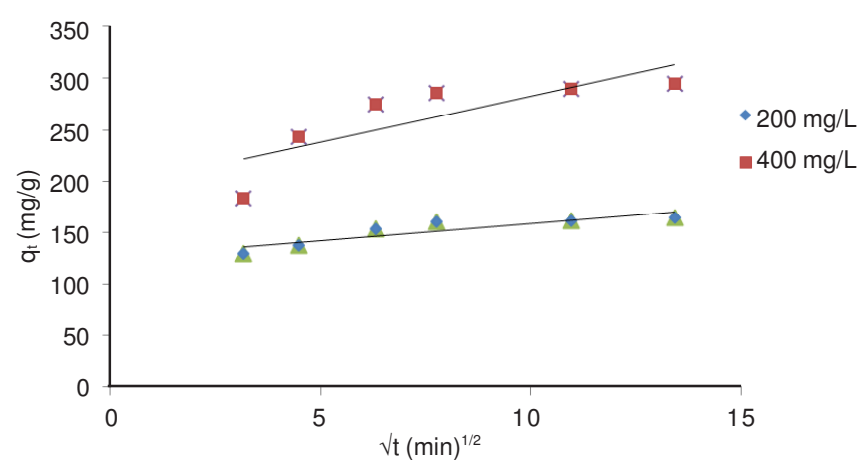

Fig. 13. Intra-particle diffusion for the adsorption of 4-nitrophenol onto activated carbon fiber

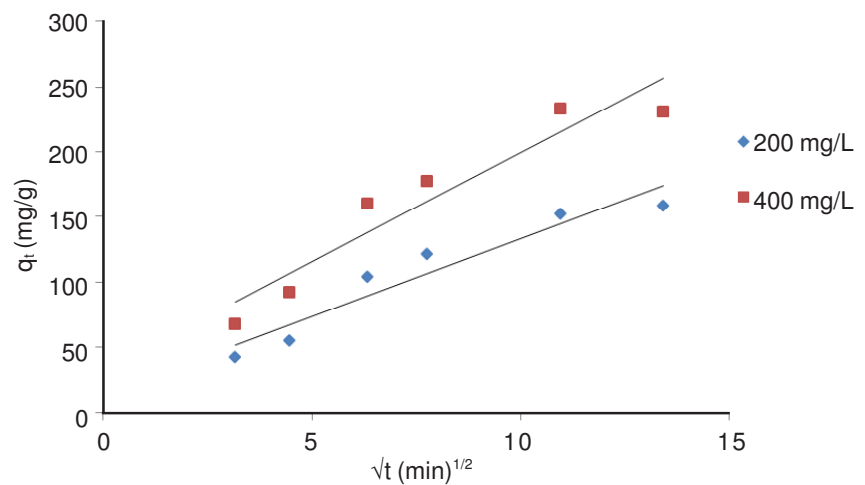

Fig. 14. Intra-particle diffusion for the adsorption of 4-nitrophenol onto commercial commercial granular activated carbon 
In the case of the commercial granular activated carbon, although the correlation coefficient values for both pseudofirst-order and pseudo-second-order kinetics models are high $\left(\mathrm{R}^{2}>0.900\right)$, the calculated adsorption capacity values $\left(\mathrm{q}_{\mathrm{e}} \mathrm{mg} /\right.$ g) of the pseudo-first-order equation fit well with the experimental $\mathrm{q}_{\mathrm{e}}$ values more than with the pseudo-second-order model. This suggest that the adsorption of 4-nitrophenol on the commercial adsorbent sample appears to be controlled by a physical process.

The regression coefficient values of the intra-particle diffusion $\left(\mathrm{R}^{2}\right)$ are $<0.790$ and $>0.900$ (Table-3) for the prepared activated carbon fiber and the commercial granular activated carbon, respectively. These values confirmed that the intraparticle diffusion mechanism was not involved in the adsorption of 4-nitrophenol on the prepared activated carbon fiber but contribute in the case of the commercial granular activated carbon. For this reason, adsorption rates of 4-nitrophenol on the prepared activated carbon is higher than that observed with the granular activated carbon as illustrated in Table-2. Additionally, it can be seen from the plot of the intra-particle diffusion (Fig. 14) that the two lines do not pass through the origin, indicating that this mechanism was not the limiting step for the rate of 4-nitrophenol adsorption on the commercial activated carbon ${ }^{42}$.

Effect of pH on adsorption: The effect of $\mathrm{pH}$ on the adsorption of 4-nitrophenol on the activated carbon fiber is illustrated in Fig. 15. When the $\mathrm{pH}$ of the solution increased from 2-5, the amount adsorbed decreases slightly. However, when the $\mathrm{pH}$ is increased to above 5, especially in the alkaline $\mathrm{pH}$ range, the adsorption of 4-nitrophenol decreased sharply. The $\mathrm{pK}_{\mathrm{a}}$ value of 4-nitrophenol is equal to $7.15^{41}$. Therefore, when the solution $\mathrm{pH}$ is lower than 5, 4-nitrophenol is present in solution in the unionized form. The net charge on the surface of activated carbon fiber was positive since the pHPZC was found to be 6.0. Thus, at low $\mathrm{pH}(e . g \cdot \mathrm{pH}=2)$ there is nearly no electrostatic repulsion between the adsorbent and the adsorbate and hence the amount adsorbed is at the maximum. Increasing the $\mathrm{pH}$ from 2 to 5 leads to the increased of 4-nitrophenolate anions in the solution as well as the number of negatively charged sites on the adsorbent. This resulted in electrostatic repulsion between the adsorbate and the adsorbent, which is the reason for the slight decrease in the amount of adsorption. At $\mathrm{pH}$ values higher than 5, almost all of the 4-nitrophenol molecules in solution are in the anionic form and the average net charge on the adsorbent surface is negative. For this reason, the amount of 4-nitrophenol adsorbed has sharply decreased due to the electrostatic repulsion between the 4-nitrophenolate anions and the adsorbent negative surface. Similar observations were aready reported ${ }^{32,41,43}$.

Effect of the temperature on adsorption: Plots of the amount adsorbed at equilibrium, $\mathrm{q}_{\mathrm{e}}(\mathrm{mg} / \mathrm{g})$ versus temperature $\left(\mathrm{T}^{\circ} \mathrm{C}\right)$ are shown in Figs. 16 and 17 for the prepared activated carbon fiber and commercial granular activated carbon, respectively. It can be seen from these figures that the amount adsorbed decreases with increasing of adsorption temperature for both tested adsorbents, indicating the apparent exothermic nature of the entire process. In the liquid phase, an increase in temperature commonly increases the solubility of the molecules

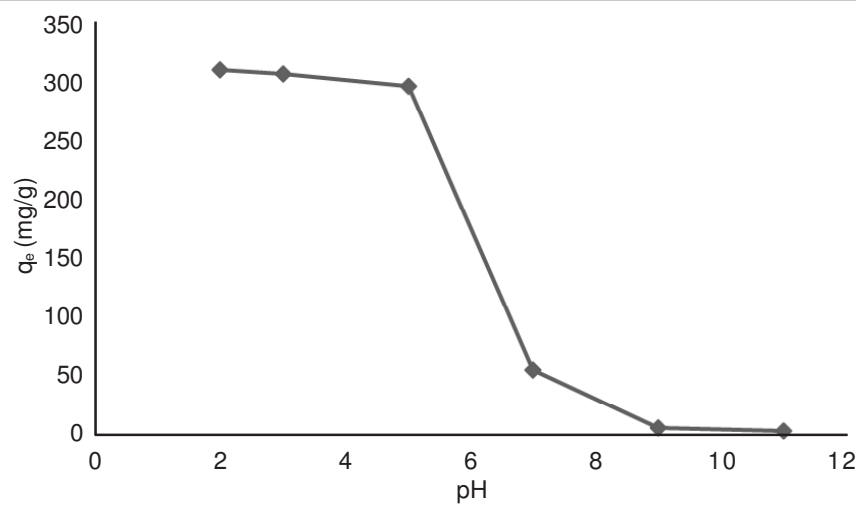

Fig. 15. Effect of $\mathrm{pH}$ on the adsorption of 4-nitrophenol onto activated carbon fiber

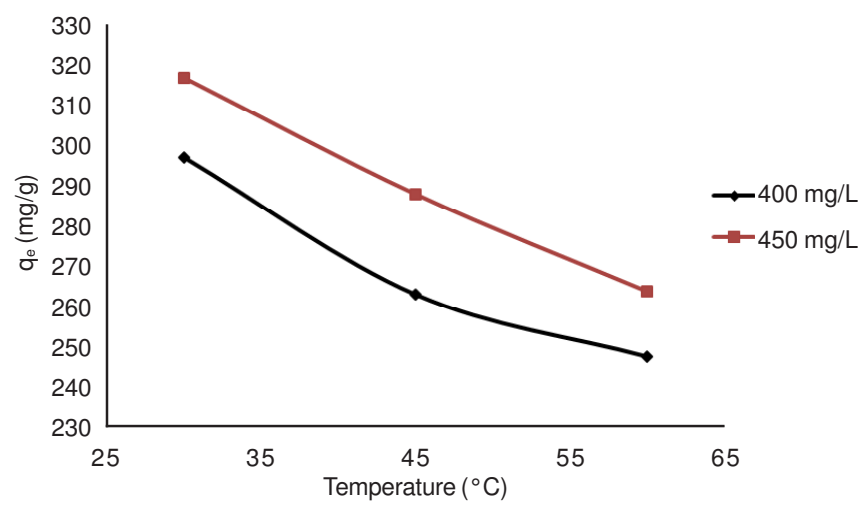

Fig. 16. Effect of temperature on the adsorption of 4-nitrophenol onto commercial activated carbon fiber

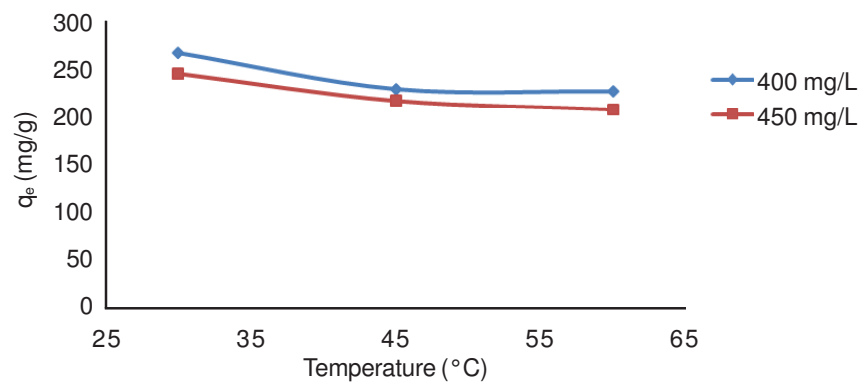

Fig. 17. Effect of temperature on the adsorption of 4-nitrophenol onto commercial granular activated carbon

and their diffusion within the pores of the adsorbent materials ${ }^{43}$ and hence less molecules of the adsorbate would be adsorbed. Similar influence has also been reported by other researchers ${ }^{41,43}$.

Thermodynamic parameters: The thermodynamic parameters for the adsorption process, $\Delta \mathrm{H}^{\circ}$ and $\Delta \mathrm{S}^{\circ}$, were calculated from the slopes and intercepts of the plots of eqn. 9;

$$
\begin{gathered}
\ln \mathrm{K}_{\mathrm{C}}=-\frac{\Delta \mathrm{H}^{\mathrm{o}}}{\mathrm{RT}}+\frac{\Delta \mathrm{S}^{\mathrm{o}}}{\mathrm{R}} \\
\mathrm{K}_{\mathrm{C}}=\frac{\mathrm{q}_{\mathrm{e}}}{\mathrm{C}_{\mathrm{e}}}
\end{gathered}
$$

where $\Delta \mathrm{H}^{\circ}$ and $\Delta \mathrm{S}^{\circ}$ are the change in enthalpy $(\mathrm{KJ} / \mathrm{mol})$ and entropy $(\mathrm{KJ} /(\mathrm{mol} \mathrm{K}))$, respectively. $\mathrm{R}$ is the universal gas constant $[8.314 \mathrm{~J} /(\mathrm{K} \mathrm{mol})]$ and $\mathrm{T}$ is the adsorption temperature $(\mathrm{K})$.

$\Delta \mathrm{G}^{\mathrm{o}}$ values at each temperature were evaluated from the obtained values of $\Delta \mathrm{H}^{\circ}$ and $\Delta \mathrm{S}^{\circ}$ using Gibb's equation (eqn. 10);

$$
\Delta \mathrm{G}=\Delta \mathrm{H}-\mathrm{T} \Delta \mathrm{S}
$$


TABLE-4

THERMODYNAMIC DATA FOR THE ADSORPTION OF 4-NITROPHENOL ONTO ACTIVATED CARBON FIBER AND GRANULAR ACTIVATED CARBON EVALUATED AT DIFFERENT AMOUNT ADSORBED AT EQUILIBRIUM AND DIFFERENT TEMPERATURES

\begin{tabular}{lcccccc}
\hline \multirow{2}{*}{ Adsorbent } & $\begin{array}{c}\text { Initial concentration } \\
(\mathrm{mg} / \mathrm{L})\end{array}$ & $\Delta \mathrm{H}^{\circ}(\mathrm{kJ} / \mathrm{mol})$ & $\Delta \mathrm{S}^{\circ}(\mathrm{KJ} / \mathrm{mol})$ & \multicolumn{3}{c}{$\Delta \mathrm{G}^{\circ}(\mathrm{KJ} / \mathrm{mol})$} \\
\cline { 5 - 8 } & 400 & -29.46 & -0.082 & -4.614 & -3.384 & -2.154 \\
\multirow{2}{*}{ Activated carbon fiber } & 450 & -23.41 & -0.065 & -3.715 & -2.74 & -1.765 \\
& 400 & -17.76 & -0.049 & -2.913 & -2.178 & -1.443 \\
\multirow{2}{*}{ Granular activated carbon } & 450 & -14.54 & -0.041 & -2.117 & -1.502 & -0.887 \\
\hline
\end{tabular}

Values of these three parameters $\left(\Delta \mathrm{H}^{\circ}, \Delta \mathrm{S}^{\mathrm{o}}, \Delta \mathrm{G}^{\mathrm{o}}\right)$ for the adsorption of 4-nitrophenol on activated carbon fiber and commercial granular activated carbon are listed in Table-4.

As shown in Table-4, the values of the enthalpy change are negative, indicating that the adsorption of 4-nitrophenol on these two adsorbents are exothermic. Moreover, the $\Delta \mathrm{H}^{\circ}$ values for the adsorption of 4-nitrophenol onto the prepared activated carbon fiber $(29.46$ and $23.41 \mathrm{KJ} / \mathrm{mol})$ are higher than $20.9 \mathrm{KJ} / \mathrm{mol}$ whereas, in the case of the commercial activated carbon the thermodynamic parameter values (17.76 and $14.54 \mathrm{KJ} / \mathrm{mol}$ ) are between 2.1 and $20.9 \mathrm{KJ} / \mathrm{mol}$. This indicates that the adsorption of 4-nitrophenol can be classified as chemisorption and physisorption ${ }^{44,45}$ for the prepared activated carbon fiber and the commercial granular activated carbon, respectively. This conclusion can also be confirmed by the results observed in the kinetics studies. Furthermore, the prepared activated carbon fiber shows higher adsorption enthalpy changes than the commercial activated carbon, which indicates that the prepared activated carbon has a stronger affinity for 4-nitrophenol in aqueous solution than the commercial one ${ }^{46}$. This is in agreement the results of the isotherm studies.

The values of the adsorption entropy changes $\left(\Delta S^{\circ}\right)$ are negative, which is indicative of the fact that the mobility of adsorbate on the surface of adsorbents is being more restricted as compared with that of those in solution. Moreover, Table-4 demonstrates the values of this thermodynamic parameter in the case of the prepared activated carbon fiber as being higher than the values for the commercial granular activated carbon. This is because the micropores of the granular activated carbon are in a more orderly arrangement ${ }^{46}$.

The negative values of the adsorption free energy $\left(\Delta \mathrm{G}^{\mathrm{o}}\right)$ (Table-4) demonstrate that the adsorptions investigated are spontaneous processes. Moreover, it can be observed that the values of $\Delta \mathrm{G}^{\circ}$ are reduce with increasing initial concentration of 4-nitrophenol or rising adsorption temperature. This suggests that at a larger initial concentration and higher temperature, the reverse process of adsorption-desorption could be easily achieved $^{41}$. It can also be observed for each concentration and at any adsorption temperature that the value of $\Delta \mathrm{G}^{\mathrm{o}}$ for the granular activated carbon is always smaller than that for the prepared activated carbon. This confirms that the prepared sample has a stronger adsorption affinity towards 4-nitropheol compound than that of the commercial one. The thermodynamic results obtained in this study are in agreement with the results observed by other researchers ${ }^{41,43,46}$.

\section{Conclusion}

The chemical activation method was applied in this work for the preparation of activated carbon from coconut husk fiber under optimal experimental conditions using $\mathrm{ZnCl}_{2}$ as the chemical activator. The results obtained indicate that the prepared activated carbon fiber has significant adsorptive properties. Adsorption of 4-nitrophenol by the prepared activated carbon fiber and the commercial granular activated carbon in a batch system was investigated. The granular activated carbon was used as a reference in evaluating the adsorption performance of the prepared activated carbon fiber. The amounts of 4nitrophenol adsorbed by both of these two adsorbents were strongly influenced by the initial concentration of the adsorbate, agitation time, solution $\mathrm{pH}$ and temperature. The adsorbed amount decreased with increasing temperature, indicating an exothermic process. Adsorption reached equilibrium within 1 and $3 \mathrm{~h}$ in the case of the prepared activated carbon fiber and commercial granular activated carbon, respectively. Langmuir and Freundlich models were used to inspect the adsorption isotherms. The Langmuir equation described the experimental data better than the Freundlich. The parameters of the isotherms such as $\mathrm{q}_{\max }$ and $\mathrm{K}_{\mathrm{F}}$ confirm that the adsorption efficiency of the prepared activated carbon is higher than that of the commercial one. Pseudo-second-order kinetic model fits very well with the experimental data of the prepared activated carbon and the experimental kinetic data of the granular activated carbon are in better agreement with the pseudo-firstorder kinetic model than the pseudo-second order. Intra-particle diffusion was only involved in the case of the commercial activated carbon. The adsorption rate of the prepared activated carbon fiber sample is always higher than that of the commercial granular activated carbon. The thermodynamic parameters were all negative. This indicates that the adsorption of each adsorbent used in this work is an exothermic and a spontaneous process and the mobility of the adsorbate on the surface of the adsorbent becomes more restricted compared with that of those in the solution. Moreover, the absolute values of the adsorption thermodynamic factors in the prepared activated carbon are higher than that of the commercial activated carbon, which shows that the adsorption affinity of the prepared sample to 4-nitrophenol is larger than that of the reference granular activated carbon. This confirms that the coconut husk fiberbased activated carbon will have a greater application capability in the field of wastewater treatment than any of the commercially available activated carbon.

\section{ACKNOWLEDGEMENTS}

The authors acknowledged the research grant provided by the University of Malaya under the IPPP Grant No. PV0352011A. 


\section{REFERENCES}

1. A. Dabrowski, P. Podkoscielny, Z. Hubicki and M. Barczak, Chemosphere, 58, 1049 (2005)

2. J. Yin, R. Chen, Y. Ji, C. Zhao, G. Zhao and H. Zhang, Chem. Eng. J., 157, 466 (2010).

3. S.-H. Lin and R.-S. Juang, J. Environ. Manage., 90, 1336 (2009).

4. A. Ersöz, A. Denizli, I. Sener, A. Atilir, S. Diltemiz and R. Say, Sep. Purif. Technol., 38, 173 (2004).

5. S. Senel, A. Kara, G. Alsancak and A. Denizli, J. Hazard. Mater., 138 317 (2006).

6. O. Hamdaoui and E. Naffrechoux, J. Hazard. Mater., 147, 381 (2007).

7. A. Ayar, S. Gürsal, A. Gürten and O. Gezici, Desalination, 219, 160 (2008).

8. Y. Ku and K.C. Lee, J. Hazard. Mater., 80, 59 (2000).

9. M. Ahmaruzzaman, Adv. Colloid Interf., 143, 48 (2008).

10. Q. Lu and G.A. Sorial, J. Hazard. Mater., 167, 89 (2009).

11. Q. Lu and G.A. Sorial, Chemosphere, 55, 671 (2004).

12. M. Suzuki, Carbon, 32, 577 (1994).

13. N.H. Phan, S. Rio, C. Faur, L. Le Coq, P. Le Cloirec and T.H. Nguyen, Carbon, 44, 2569 (2006).

14. M.A.A. Zaini, Y. Amano and M. Machida, J. Hazard. Mater., 180, 552 (2010).

15. A. Castro-Muñiz, F. Suárez-García, A. Martínez-Alonso and J.M.D. Tascón, J. Colloid Interf. Sci., 361, 307 (2011).

16. F. Rodriguez-Reinoso, A.C. Pastor, H. Marsh and A. Huidobro, Carbon, 38, 397 (2000).

17. M.C. Blanco López, A. Martínez-Alonso and J.M.D. Tascón, Micropor. Mesopor. Mater., 34, 171 (2000).

18. J.-P. Wang, H.-M. Feng and H.-Q. Yu, J. Hazard. Mater., 144, 200 (2007),

19. Y. Hamamoto, K.C.A. Alam, B.B. Saha, S. Koyama, A. Akisawa and T. Kashiwagi, Int. J. Refrig., 29, 305 (2006).

20. S.-J. Park, Y.-S. Jang, J.-W. Shim and S.-K. Ryu, J. Colloid Interf. Sci., 260, 259 (2003).

21. A. Macías-García, E.M. Cuerda-Correa, M. Olivares-Marín, A. DíazParalejo and M.Á. Díaz-Díez, Ind. Crops Prod., 35, 105 (2012).

22. F.F. Avelar, M.L. Bianchi, M. Gonçalves and E.G. da Mota, Bioresour Technol., 101, 4639 (2010).
23. S. Aber, A. Khataee and M. Sheydaei, Bioresour. Technol., 100, 6586 (2009).

24. K. Li, Z. Zheng, J. Feng, J. Zhang, X. Luo, G. Zhao and X. Huang, J. Hazard. Mater., 166, 1180 (2009).

25. K. Li, Z. Zheng and Y. Li, J. Hazard. Mater., 181, 440 (2010).

26. D. Mohan, K.P. Singh and V.K. Singh, J. Hazard. Mater., 135, 280 (2006).

27. I.A.W. Tan, B.H. Hameed and A.L. Ahmad, Chem. Eng. J., 127, 111 (2007).

28. Q. Lu and G.A. Sorial, J. Hazard. Mater., 148, 436 (2007).

29. B.M. Babic, S.K. Milonjic, M.J. Polovina and B.V. Kaludierovic, Carbon, 37, 477 (1999).

30. A. Dabrowski, Adv. Colloid Interf., 93, 135 (2001).

31. A.A. Ahmad, B.H. Hameed and N. Aziz, J. Hazard. Mater., 141, 70 (2007).

32. C. Moreno-Castilla, Carbon, 42, 83 (2004).

33. X. Liu and N.G. Pinto, Carbon, 35, 1387 (1997).

34. G. Atun, G. Hisarli, W.S. Sheldrick and M. Muhler, J. Colloid Interf. Sci., 261, 32 (2003)

35. T. W. Webi and R.K. Chakravort, AIChE J., 20, 228 (1974).

36. A. Fisal, W.M.A.W. Daud, M.A. Ahmad and R. Radzi, Chem. Eng. J., 178, 461 (2011).

37. Q. Lu and G.A. Sorial, J. Hazard. Mater., 167, 89 (2009).

38. E. Ayranci and O. Duman, J. Hazard. Mater., 124, 125 (2005).

39. V.K. Gupta, Ind. Eng. Chem. Res., 37, 192 (1998).

40. M. Ajmal, R. Ali Khan Rao, S. Anwar, Bioresour. Technol., 86, 147 (2003).

41. D. Tang, Z. Zheng, K. Lin, J. Luan and J. Zhang, J. Hazard. Mater., 143, 49 (2007).

42. G. McKay and V.J.P. Poots, J. Chem. Technol. Biotechnol., 30, 279 (1980).

43. L.M. Cotoruelo, M.D. Marqués, F.J. Díaz, J. Rodríguez-Mirasol, J.J. Rodríguez and T. Cordero, Chem. Eng. J., 184, 176 (2012).

44. A. Kurniawan and S. Ismadji, J. Taiwan Inst. Chem. E, 42, 826 (2011).

45. S.K. Theydan and M.J. Ahmed, J. Anal. Appl. Pyrol., 97, 116 (2012).

46. A. Li, H. Wu, Q. Zhang, G. Zhang, C. Long, Z. Fei, F. Liu and J. Chen, Chinese J. Polym. Sci., 22, 259 (2004). 